\title{
Reconhecer para enfrentar: práxis pedagógica antirracista na educação física escolar
}

\author{
Recognize to face: anti-racist pedagogical practice in school physical education \\ Reconocer a la cara: praxis pedagógica antirracista en la educación física escolar \\ Denise Aparecida Corrêa ${ }^{1}$; Paloma de CAMPos Rodrigues ${ }^{2}$ \\ Universidade Estadual Paulista “Júlio de Mesquita Filho", UNESP, BaURU-SP, Brasil
}

\section{RESUMO}

Este artigo buscou compreender e caracterizar a práxis pedagógica antirracista nas aulas de educação física na perspectiva docente. Com abordagem metodológica qualitativa, o estudo envolveu pesquisa bibliográfica e de campo da qual participaram oito docentes do componente curricular educação física no ensino fundamental. A análise das narrativas das docentes revelou o comprometimento da educação antirracista com o enfrentamento ao currículo eurocêntrico e monocultural. A fruição de manifestações culturais de matrizes africanas e indígenas, atrelada ao diálogo e reflexão para desconstrução de estereótipos e preconceitos, perpassou a práxis pedagógica antirracista das docentes, a qual se mostrou comprometida com a democratização dos conhecimentos, com o engajamento da comunidade escolar e estímulo ao protagonismo dos/as educandos. Consideramos primordial o fomento à formação docente inicial e continuada para ampliação e efetivação da educação antirracista na escola. Palavras-chave: Antirracismo. Práxis Docente. Educação Física Escolar.

\begin{abstract}
This article sought to understand and characterize the anti-racist pedagogical praxis in physical education classes from a teaching perspective. With a qualitative methodological approach, the study involved bibliographical and field research in which eight teachers of the physical education curriculum component in elementary school participated. The analysis of the teachers' narratives revealed the commitment of anti-racist education to confront the eurocentric and monocultural curriculum. The fruition of cultural manifestations from african and indigenous matrices, coupled with dialogue and reflection to deconstruct stereotypes and prejudices, permeated the anti-racist pedagogical praxis of teachers, which proved to be committed to the democratization of knowledge, with the engagement of the school community and encouragement to the role of the students. We consider it essential to encourage initial and continuing teacher education to expand and implement anti-racist education in schools.
\end{abstract}

Keywords: Anti-Racism. Teaching Praxis. School Physical Education.

\section{RESUMEN}

Este artículo buscó comprender y caracterizar la praxis pedagógica antirracista en las clases de educación física desde una perspectiva docente. Con un enfoque metodológico cualitativo, el estudio involucró una investigación bibliográfica y de campo en la que participaron ocho docentes del componente curricular de educación física en la escuela primaria. El análisis de las narrativas de los profesores reveló el compromiso de la educación antirracista para enfrentar el currículo eurocéntrico y monocultural. La fructificación de manifestaciones culturales desde matrices africanas e indígenas, sumadas al diálogo y la reflexión para deconstruir estereotipos y prejuicios, impregnaron la praxis pedagógica antirracista de los docentes, que se mostraron comprometidos con la democratización del conocimiento, con el compromiso de la comunidad escolar y estímulo al rol de los estudiantes. Consideramos fundamental fomentar la formación docente inicial y continua para ampliar e implementar la educación antirracista en las escuelas.

Palabras clave: Antirracismo. Praxis Docente. Educación Física Escolar.

\footnotetext{
1 Professora da Faculdade de Ciências, Departamento de Educação Física da Unesp Bauru. E-mail: deapcorrea@gmail.com. ORCID: https://orcid.org/0000-0001-9890-7476.

${ }^{2}$ Licenciada em Educação Física e estudante do Curso de Bacharelado em Educação Física da Unesp Bauru. Email: palomarodrigues1999@ hotmail.com. ORCID: https://orcid.org/0000-0002-3357-2430.
} 


\section{INTRODUÇÃO}

Parafraseando a obra de Santos (2003), o título deste artigo remete ao que Cavalleiro (2001), no início deste século, anunciava como ponto de partida para empreender a educação antirracista: reconhecer a existência do racismo na sociedade brasileira e na escola é condição para enfrentá-lo.

Isto implica compreender os mecanismos que historicamente estruturaram o racismo e, reconhecendo-os, engajarmos nas lutas emancipatórias e de mobilização antirracistas, pois "Nessas resistências e em suas articulações locais/globais reside o impulso da globalização contra hegemônica" (SANTOS; NUNES, 2003, p. 61).

$\mathrm{O}$ racismo compreendido como uma lógica estruturante possibilita situar historicamente a sociedade brasileira no interior da dominação colonial, que relegou aos escravizados africanos e seus descendentes trazidos forçadamente ao território brasileiro, a condição de marginalização e desqualificação, a partir do princípio organizador "[...] que divide tudo entre as formas e os seres superiores (civilizados, hiper-humanizados, etc., acima da linha do humano) e outras formas de seres inferiores (selvagens, bárbaros, desumanizados, etc. abaixo da linha do humano)" (GROSFOGUEL, 2020, p. 59).

Grosfoguel (2020) argumenta que o racismo, na perspectiva da colonialidade, é o princípio fundante e estruturador das demais relações sociais de dominação “[...] desde divisão internacional do trabalho até as hierarquias epistêmicas, sexuais, de gênero, religiosas, pedagógicas, médicas, junto com as identidades e subjetividades" (p. 59).

No contexto brasileiro atual é ainda mais imperiosa essa retomada histórica, haja vista, discursos com contornos ideológicos que propalam o "mito da democracia racial", o qual, "Concebido e propagado por sociólogos pertencentes à elite econômica na metade do século XX [...] afirma que no Brasil houve a transcendência dos conflitos raciais pela harmonia entre negros e brancos, traduzida na miscigenação e na ausência de leis segregadoras" (RIBEIRO, 2019, p. 18-19)

Os efeitos perversos destes discursos que reverberam uma falsa harmonia em uma sociedade historicamente marcada pela hierarquia racial, são de perpetuarem as relações de opressão e de violência, revelando a complexidade para se combater o racismo em uma sociedade que não se reconhece racista. Assim, o ato de não falar sobre, de não nomear, e de romantizar as violências sofridas pelo povo negro, são duplamente perigosas: ao passo que contribui para manutenção do racismo, imobiliza ações antirracistas (RIBEIRO, 2019).

Cavalleiro (2001) ao problematizar a educação antirracista revelou o efeito perverso do racismo no sistema escolar, identificando que estudantes negros e negras apresentam maior índice de evasão e repetência, bem como, maior saída e retorno ao sistema de ensino, na tentativa de driblar as adversidades impostas pela desigualdade racial para manter-se na escola apesar das dificuldades.

Como narrou Ribeiro (2019) foi no início de sua trajetória escolar como uma criança negra, se percebeu como um problema para a sociedade, procurando se ajustar ao que lhe era apresentado como "normal":

O mundo apresentado na escola era o dos brancos, no qual as culturas europeias eram vistas como superiores, o ideal a ser seguido. Eu reparava que minhas colegas brancas não precisavam pensar no lugar social da branquitude, pois eram vistas como normais: a errada era eu [...] Essa divisão social existe há séculos e é exatamente a falta de reflexão sobre o tema que constituiu um das bases para a perpetuação do sistema de discriminação racial (p. 24-25).

Em acordo com Silva (2007) a escola ao negligenciar os conhecimentos e experiências de ser, viver e pensar de descendentes de africanos e indígenas reforçando a ideia de uma 
sociedade monocultural e, empobrecida culturalmente, entendendo a diversidade como riqueza e não um demérito, pois, "Corpos negros, brancos, indígenas, mestiços, doentes, sadios, gordos, magros, com deficiências, produzem conhecimentos distintos, todos igualmente humanos e, por isso, ricos em significados" (p. 501).

Neste aspecto reside o paradoxo da instituição escolar brasileira, que ao mesmo tempo em que atuou perpetuando desigualdades diante do silêncio e da estagnação frente ao sistema de discriminação racial, ela tem um papel preponderante de transformação e de atuação no sentido de projetar uma sociedade justa, equânime e solidária.

A intensa mobilização do Movimento Negro na luta, pressão e resistência em busca de uma educação fundamentada na superação do racismo no ambiente escolar decorreram de políticas educacionais que favoreceram e impulsionaram o debate e as ações neste campo (GOMES, 2011).

A partir de 2003 a Lei de Diretrizes e Bases da Educação Nacional foi alterada por meio das Leis Federais 10639/2003 e 11645/2008 tornando obrigatório o ensino da História e Cultura Africana, Afro-brasileira e Indígena nas escolas públicas e particulares brasileiras (BRASIL, 2008).

Para subsidiar o trabalho docente e traçar orientações para o cumprimento das referidas leis, as Diretrizes Curriculares Nacionais Para a Educação das Relações ÉtnicoRaciais e para o Ensino de História e Cultura Afro-Brasileira e Africana, se tornou um documento essencial para a implementação de práticas pedagógicas antirracistas na escola, dado seu papel fundamental "[...] para eliminação das discriminações e para emancipação dos grupos discriminados, ao proporcionar acesso aos conhecimentos científicos, a registros culturais diferenciados, à conquista de racionalidade que rege as relações sociais e raciais" (BRASIL, 2004, p. 14).

Cabe assinalar que, na década de 1990, os Parâmetros Curriculares Nacionais (PCNs) evidenciaram a importância de:

Conhecer e valorizar a pluralidade do patrimônio sociocultural brasileiro, bem como aspectos socioculturais de outros povos e nações, posicionando-se contra qualquer discriminação baseada em diferenças culturais, de classe social, de crença, de sexo, de etnia ou características individuais e sociais (BRASIL, 1997, p. 7).

A Educação Física como componente curricular obrigatório da Educação Básica tem um papel relevante em promover a diversidade cultural visando uma escola mais igualitária e democrática, como já indicava os PCNs:

A Educação Física permite que se vivenciem diferentes práticas corporais advindas das mais diversas manifestações culturais e se enxergue como essa variada combinação de influências está presente na vida cotidiana. As danças, esportes, lutas, jogos e ginásticas compõem um vasto patrimônio cultural que deve ser valorizado, conhecido e desfrutado. Além disso, esse conhecimento contribui para a adoção de uma postura não-preconceituosa e discriminatória diante das manifestações e expressões dos diferentes grupos étnicos e sociais e às pessoas que dele fazem parte (BRASIL, 1997, p. 24).

Assim, a Educação Física na escola pode possibilitar acesso a um vasto universo cultural, cujas manifestações lúdicas, como jogos, brinquedos e brincadeiras de diferentes matrizes culturais africanas, afro-brasileiras e indígenas, contribuem para valorização e fortalecem o pertencimento étnico identitário de crianças e jovens na escola (MARANHÃO; GONÇALVES JUNIOR; CORRÊA, 2007). 
É preciso pontuar que significativos trabalhos vêm sendo empreendidos por professores e professoras, tornando expressivo o trabalho pedagógico que contribui para uma educação antirracista na educação física escolar.

Miranda (2017) pesquisou quatro professoras de Educação Física Escolar da rede pública, atuantes em diferentes níveis de ensino da Educação Básica e identificou que a atuação docente antirracista se mostrou efetiva e com resultados positivos para a comunidade escolar. A autora argumentou a favor do investimento na formação inicial e continuada de professores/as, atentando-se para o trabalho pedagógico com tais conteúdos de forma contínua para além das abordagens pontuais em datas ou semanas festivas.

Como educadores/as é necessário nos posicionar visando uma sociedade justa, que valorize e respeite a diversidade, fazendo com que a Educação Física na escola seja um espaço de reflexão, desconstrução de visões preconceituosas e que favoreça o respeito entre todos e todas: "A educação das relações étnico-raciais impõe aprendizagens entre brancos e negros, troca de conhecimentos, quebra de desconfianças, projeto conjunto para construção de uma sociedade justa, igual, equânime" (BRASIL, 2004, p. 14)

Nessa perspectiva precisamos estar dispostos a romper com a educação em uma concepção bancária e refletir se possibilitamos aos educandos/as a criticidade, o conhecimento de mundo e a problematização de modo a prepará-los/as para se tornarem agentes transformadores, sejam através de ações, ou pela perpetuação do pensamento crítico, do reconhecimento de sua realidade.

Compreendendo a relevância da educação física escolar neste contexto, propomos investigar a práxis docente, pois acreditamos ser ela meio de mobilização e construção de conhecimentos, visando a superação da estagnação da educação bancária, uma vez que:

[...] fora da práxis, os homens não podem ser. Educador e educandos se arquivam na medida em que, nesta destorcida visão da educação, não há criatividade, não há transformação, não há saber. Só existe saber na invenção, na reinvenção, na busca inquieta, impaciente, permanente, que os homens fazem no mundo, com o mundo e com os outros (FREIRE, 2005, p. 33).

Nesse cenário, dada relevância de investigar práticas pedagógicas antirracistas na Educação Física Escolar, as seguintes questões balizam este estudo: como professores/as de Educação Física significam a educação antirracista e como a efetivam nas aulas deste componente curricular na escola?

Tendo em vista tais questões, neste artigo buscamos compreender e caracterizar a práxis pedagógica antirracista nas aulas de educação física na perspectiva docente.

\section{RACISMO E ANTIRRACISMO NA EDUCAÇÃo FísICA}

Ao nos debruçarmos sobre os estudos envolvendo a questão racial nas aulas de educação física, traçamos um diálogo com Paulo Freire na perspectiva da denuncia/anúncio, e na confluência da denuncia da desigualdade racial, vislumbrar o anúncio traçando rotas e caminhos para enfrentá-lo.

Santos (2007) em sua pesquisa acerca dos estudantes negros nas aulas de educação física observou a recorrência de apelidos pejorativos de cunho racista durante as brincadeiras e jogos, e mesmo diante do desconforto demonstrado pelo/a estudante que sofria a agressão, não emergia nas aulas como problemática a ser dialogada.

Como salienta Almeida (2018): 
Consciente de que o racismo é parte da estrutura social e, por isso, não necessita de intenção para se manifestar, por mais que calar-se diante do racismo não faça do indivíduo moral e/ou juridicamente culpado ou responsável, certamente o silêncio o torna ética e politicamente responsável pela manutenção do racismo. A mudança da sociedade não se faz apenas com denúncias vazias ou repúdio moral do racismo: depende, antes de tudo, da tomada de posturas e da adoção de práticas antirracistas (p.40).

Infelizmente este é um cenário que reflete muitos cotidianos escolares, em que as agressões e violências racistas não são enfrentadas e geralmente têm um desfecho com um pedido de "desculpas", sem que seja debatido e levado ao grupo para diálogo e reflexão, o que fortalece o sistema de discriminação racial na escola (CAVALLEIRO, 2005).

A este respeito Gomes (2012) ressalta que:

[...] a discriminação racial se faz presente como fator de seletividade na instituição escolar e o silêncio é um dos rituais pedagógicos por meio do qual ela se expressa. Não se pode confundir esse silêncio com o desconhecimento sobre o assunto ou a sua invisibilidade. É preciso colocá-lo no contexto do racismo ambíguo brasileiro e do mito da democracia racial e sua expressão na realidade social e escolar. $\mathrm{O}$ silêncio diz de algo que se sabe, mas não se quer falar ou é impedido de falar. No que se refere à questão racial, há que se perguntar: por que não se fala? Em que paradigmas curriculares a escola brasileira se pauta a ponto de "não poder falar" sobre a questão racial? (p. 105).

Outro aspecto a considerar é a necessidade pertencermos a grupos identitários, especialmente na infância, é muito marcante a aprendizagem entre pares e para além da faixa etária, estes grupos se estabelecem pautados em habilidades e fenótipos. Na pesquisa realizada por Maranhão (2009) em uma das aulas de educação física, a primeira com atividade em grupo, uma criança negra não foi aceita por colegas com a justificativa que os grupos estavam completos. $\mathrm{O}$ constrangimento foi tanto, que a criança se retirou da atividade e se escondeu pela escola.

Como identificado na pesquisa de Santos (2007) em uma situação em que um dos estudantes optou por não participar de um torneio de jogos, a ter que tirar o boné e, diante da fala do professor que era algo muito simples de resolver, o estudante respondeu "[...] que talvez fosse fácil para ele que 'tem cabelinho bom', mas no seu caso, que está 'com uma juba' e 'a raça não ajuda', melhor ficar fora a 'passar vergonha na frente dos outros e das gurias'" (p. 133-134).

Neste cenário, infelizmente, “[...] crianças e adolescentes negros se veem forçados a recorrer, desde muito cedo, a estratégias de resistência para combater as práticas preconceituosas e discriminatórias que sofrem" (OLIVEIRA et al., 2020, p.169).

Estas violências cotidianas afetam sobremaneira o desenvolvimento dos/as educandos/as negras, intensificando processos de auto rejeição e sendo responsável pela menor participação em ambientes de aprendizagem escolar significativos como as aulas de Educação Física.

Segundo Silva (2003) situações em que educandos/as negros/as são chamados por colegas e professores/as por apelidos pejorativos e expressões e frases de cunho racistas disfarçados "brincadeiras", que nada têm de lúdicas, potencializam o racismo e faz com que seja internalizado.

Racismo, preconceito e discriminação no contexto escolar geram sofrimento e prejuízos, preponderantemente para os/as estudantes negros/as, que desenvolvem "[...] ausência de reconhecimento positivo de seu pertencimento racial; dificuldades no processo de aprendizagem; recusa em ir à escola e, consequentemente, evasão escolar", enquanto que: "Para o aluno branco [...] acarretam a cristalização de um sentimento irreal de superioridade, 
proporcionando a criação de um círculo vicioso que reforça a discriminação racial no cotidiano escolar, bem como em outros espaços da esfera pública" (CAVALLEIRO, 2005, p. 12).

De acordo com Rangel (2006), uma formação docente que capacite professores/s a identificarem situações de discriminação racial nas aulas de educação física e busque compreender como se manifestam, é capaz de reconhecê-las, em ações e gestos sutis, como por exemplo, uma criança não querer dar a mão para outra, não partilhar brinquedos ou não querer participar da quadrilha, entre outros (RANGEL, 2006).

Diante diversidade de conteúdos da cultural corporal que podem e devem ser exploradas neste componente curricular, as aulas de educação física têm um potencial pedagógico para criar de forma lúdica e divertida, ampliação e aprofundamento de conhecimentos de forma consistente e planejada, na perspectiva de valorizar a história e fortalecer o pertencimento de suas raízes identitárias para as crianças negras e indígenas, atentando-se em não reforçar os estereótipos, ocasionando a invisibilização de seus povos e suas culturas.

Acreditamos que o acesso ao conhecimento emancipa, assim o primeiro passo para enfrentar o racismo é reconhecer sua existência, para que possamos intervir e fomentar a educação antirracista a qual:

[...] visa à erradicação do preconceito, das discriminações, e de tratamentos diferenciados. Nela, estereótipos e ideias preconcebidas, estejam onde estiverem (meio de comunicação, material didático e de apoio, corpo discente, docente etc.), precisam ser duramente criticados e banidos (CAVALLEIRO, 2001, p. 150).

Portanto, a educação antirracista se fundamenta em conhecer, reconhecer e questionar tudo aquilo que dificulta e até mesmo impede pessoas pertencentes aos grupos alvos do sistema de discriminação racial, o direito de reconstruir sua identidade de forma positiva e com orgulho (CAVALLEIRO, 2001).

Nesse sentido, a educação antirracista precisa ser consistente, um compromisso de todos os envolvidos na área educacional. Não é possível realizar uma educação antirracista sem que haja uma preparação da gestão e dos professores, que em muitos casos internalizaram o senso comum e o aplicam em sua prática pedagógica (SILVA, 2005).

Como observado na pesquisa de Maranhão e Gonçalves Junior (2009) realizada com crianças dos anos iniciais do Ensino Fundamental, ao buscar suas descendências surgiram "Francês", "Italiano", "Português", "Alemão", nenhuma menção à "Africana", ainda que, em sua maioria, fossem crianças negras. Após a realização de planejamento voltado aos jogos, brincadeiras, danças, cantos e contos afro-brasileiros e africanos nas aulas de educação física, os resultados indicaram outra percepção das crianças acerca do continente Africano, valorização da cultura negra e consequentemente da população afrodescendente.

Na pesquisa com a confecção e recriação dos jogos de tabuleiro africanos Yote e Senet nas aulas de Educação Física com uma turma do $6^{\circ}$ ano dos Anos Finais do Ensino Fundamental, Silva (2019) observou, para além da valorização da origem histórica dos jogos, a ressignificação de concepções negativas acerca do continente africano, as quais foram paulatinamente, a cada aula sendo desconstruídas e adquirindo novos significados, com o reconhecimento da África como um continente e a alusão aos países de origem dos jogos permeados por expressões positivas.

Pesquisa realizada por Corrêa, Silva e Carvalho (2020) envolvendo os jogos de tabuleiro, com estudantes do Ensino Médio, demonstrou a relevância que os estudantes atribuíram no sentido de conhecer culturas e histórias de povos até então desconhecidos, denunciando a ausência deste conteúdo durante toda a escolarização. Nos relatos, chamou a 
atenção, que os/as estudantes lamentaram terem tido acesso a esse conhecimento tardiamente, nos anos finais da Educação Básica.

Ao trabalhar com os preceitos da educação antirracista propostos por Cavalleiro (2001, p.158) na educação física escolar, como a necessidade de buscar " [...] materiais que contribuam para a eliminação do 'eurocentrismo' dos currículos escolares e contemplem a diversidade racial [...]", a pesquisa de Rodrigues e Corrêa (2021) ao trabalharem a temática das Princesas Africanas com a contação de histórias e brincadeiras notaram que as crianças, para além da construção do conhecimento, reconheceram aspectos positivos na personalidade das personagens, contribuindo com a ampliação e valorização dos conhecimentos acerca de princesas negras e suas histórias.

O que os resultados destes trabalhos demonstram em suas diversas possibilidades de abordagens de diferentes conteúdos são as potencialidades pedagógicas da educação física escolar na educação antirracista evidenciando sua urgência no espaço escolar, o que nos instigam a trazer à cena, protagonistas de outros trabalhos igualmente relevantes, professoras que no dia a dia de suas aulas, seguem fortalecendo uma práxis pedagógica antirracista na educação física escolar.

\section{Percurso Metodológico}

O estudo envolveu pesquisa bibliográfica e de campo, com abordagem metodológica qualitativa, a qual "[...] se centra na descrição, análise e interpretação das informações recolhidas durante o processo investigatório, procurando entendê-las de forma contextualizada" (NEGRINE, 1999, p. 61).

Para compormos o quadro de participantes da pesquisa realizamos a formação de redes de colaboradores/as a partir de três professoras de educação física que se constituíram sujeitos referência ou pessoas chave, reconhecidas no ambiente profissional que atuam na temática em estudo (COSTA, 2018).

As três professoras referência, indicaram dois docentes, que na percepção delas, desenvolviam ações pedagógicas antirracistas em suas aulas. Esse caminho metodológico prosseguiu até que os nomes citados repetissem, fechando o círculo de indicações e a composição das professoras colaboradoras: oito professoras.

Como instrumento de coleta de dados, foi utilizado questionário (MARCONI; LAKATOS, 2003), cuja primeira parte teve o objetivo de delinear o perfil do grupo de colaboradoras (Quadro 1) caracterizado por oito professoras experientes as quais tiveram sua identificação nominal preservada em acordo com os preceitos éticos da pesquisa, sendo seus nomes reais substituídos por nomes fíctícios escolhidos por elas.

Quadro 1: Perfil das Colaboradoras da Pesquisa.

\begin{tabular}{|c|c|c|c|c|}
\hline $\begin{array}{c}\text { Docentes } \\
\text { (Nomes } \\
\text { fictícios) }\end{array}$ & $\begin{array}{c}\text { Auto } \\
\text { declaração } \\
\text { racial }\end{array}$ & Pós-graduação & $\begin{array}{c}\text { Tempo de atuação no } \\
\text { ensino fundamental }\end{array}$ & $\begin{array}{c}\text { Tempo de atuação na } \\
\text { escola atual }\end{array}$ \\
\hline Ana I & Preta & Especialização & De 2 a 5 anos & De 2 a 5 anos \\
\hline Ana II & Parda & Especialização & De 2 a 5 anos & De 2 a 5 anos \\
\hline Ana III & Branca & Mestrado & Mais de 10 anos & De 6 a 10 anos \\
\hline Andreia & Branca & $\begin{array}{c}\text { Especialização e } \\
\text { Mestrado }\end{array}$ & Mais de 10 anos & De 2 a 5 anos \\
\hline Fernanda & Branca & Mestrado & Mais de 10 anos & De 6 a 10 anos \\
\hline Flavia & Branca & Especialização & Mais de 10 anos & Mais de 10 anos \\
\hline Juliana & Branca & Mestrado & De 6 a 10 anos & De 6 a 10 anos \\
\hline Rebeca & Branca & Mestrado & Mais de 10 anos & De 6 a 10 anos \\
\hline
\end{tabular}

Fonte: Dados da pesquisa. 
A segunda parte do questionário envolveu duas perguntas fechadas sobre a incidência de manifestações de racismo e discriminação racial na escola e três perguntas abertas, a partir das quais, buscamos o relato das experiências docentes com a educação antirracista em suas aulas e como as mesmas as significam.

Diante da impossibilidade de inserção presencial em campo em razão da pandemia da Covid-19, a realização da coleta de dados desta pesquisa se deu por meio de formulário eletrônico, recorrendo à plataforma Google, por meio do Google Forms (MOTA, 2019).

O formulário eletrônico foi organizado em três etapas: a primeira etapa previu a confirmação formalizada do consentimento para participação na pesquisa com a anuência ao Termo de Consentimento Livre e Esclarecido; a segunda etapa correspondeu ao questionário e, a terceira e última etapa, contemplou a indicação de dois/duas professores/as para colaborarem com a pesquisa.

Os dados coletados foram submetidos à análise de conteúdo categorial temática a partir de Gomes (2004), possibilitando o agrupamento de elementos, ideias ou manifestações em torno do tema a ser investigado, configurando duas categorias, discutidas a seguir.

\section{A) EDUCAÇÃo ANTIRRACISTA: O QUE DIZEM AS PROFESSORAS}

No tocante às percepções das professoras sobre manifestações de racismo e discriminação racial no contexto escolar apenas uma mencionou nunca ter percebido tais situações e das sete professoras que relataram perceberem a ocorrência de tais situações na escola, todas indicaram a ocorrência de manifestações de estudantes para estudantes, o que convergem com o estudo de Santos (2007) mencionado anteriormente, que revelou a ocorrência de atitudes racistas para com os estudantes negros.

No que diz respeito às observações de situações de racismo perpetradas por professoras/es para com os/as estudantes, também foram percebidas por três professoras, número menor em relação ao agrupo de estudantes, porém não menos preocupante, assim como de estudantes para professoras/es, percebidas apenas por duas docentes.

Retomamos aqui Rangel (2006) que apontou para a necessidade de compreender que o racismo se manifesta também na sutileza de gestos, expressões, palavras e até mesmo, em atitudes de recusa de dar as mãos, abraços ou outros gestos de afeto, o que pode ferir tanto quanto ofensas e agressões declaradas.

Os relatos das professoras participantes da pesquisa possibilita compreender, como anunciado no título deste artigo, que ao passo que reconhecem o racismo no contexto escolar, lançam luzes sobre formas de efetivar a educação antirracista, concebida como "[...] uma perspectiva de educação que busca reparar as consequências do racismo estrutural [...] Busca romper com os padrões eurocêntricos presentes nos currículos [...]" (Profa. Juliana).

Interessante notar que essa percepção remete à superação daquilo que Maranhão (2009) chamou a atenção, acerca das relações étnico-raciais no contexto escolar e, sobretudo nas aulas de Educação Física terem sido "[...] marcadas em seus diferentes momentos históricos por conturbadas passagens pela invisibilidade, marginalização, opressão, desqualificação e reprodução de modelos eurocêntricos [...]" (p. 36-37).

Em consonância com o que assinalou Cavalleiro (2001) anteriormente, perpassa os relatos das professoras a busca pela superação do modelo eurocêntrico ao conceberem a educação antirracista na escola, na medida em que nas suas aulas "[...] Busca-se também, o engajamento de processos educativos para a valorização das culturas africanas, afro-brasileira e indígenas em todos os componentes curriculares" como salientou a Profa. Juliana, compartilhada pela Profa. Andreia ao mencionar que abrange: "Desenvolver atividades que 
envolvam a cultura indígena, africana, afro-brasileira e mostrar que é importante eles conhecerem suas raízes".

A compreensão de que através do conhecimento, das representações, do desenvolvimento de aulas que valorizem a cultura africana, afro-brasileira e indígena, é possível potencializarem a desconstrução dos estereótipos se fez notar no relato da Profa. Ana II acredita que "[...] seja a exaltação do negro (ao longo da história ou dentro do esporte, por exemplo)".

A partir da compreensão das professoras neste estudo, podemos demarcar as aulas de educação física conforme sinalizou Cavalleiro (2001), enquanto espaço político pedagógico privilegiado para efetivar a educação antirracista, se fazendo na fruição e nas vivências, mas, sobretudo, no diálogo e na reflexão.

Tais premissas marcam a percepção das professoras Rebeca, Ana II e Ana III, respectivamente nos relatos que seguem: "É além de trabalhar a história africana e afrobrasileira, discutir com os alunos/as, gerar uma reflexão entre eles” (Profa. Rebeca); “[...] a promoção de reflexão sobre as relações raciais; a abertura ao diálogo" (Profa. Ana II); "Discutir e refletir sobre o racismo e formas de atuação na luta contra o racismo" (Profa. Ana III).

Os relatos nos remetem ao que sinalizamos com Freire (2005), para a necessidade de engajarmos em uma educação problematizadora, pois através do reconhecimento da realidade, da situação concreta, que tornou possível o diálogo das professoras sobre suas visões do mundo e sobre as visões do mundo dos/as educandos/as, e juntos/as compreenderem como se constitui as ações e atitudes visando a desconstrução de estigmas sociais.

Acreditamos na superação da educação bancária que acomoda e se adapta, enfatizando para a necessidade de uma visão de educação com engajamento e atuação e, por isso, libertadora. Afirmamos então que: “[...] ninguém educa ninguém, como tampouco ninguém se educa a si mesmo: os homens se educam em comunhão, mediatizados pelo mundo" (FREIRE, 2005, p. 39).

A preocupação com as relações que se estabelecem com os/as educandos/as e em criar um espaço que acolha as diferenças permeia as percepções da Profa. Ana I quando diz que "Além de trabalhar às questões de relacionamento entre os alunos, permitir que eles encontrem identificação no espaço escolar" (Profa. Ana I) e a Profa. Flavia para a qual a educação antirracista é a "A educação que discute as diferenças e respeita a todos".

Neste aspecto, nos chamou a atenção o relato da Profa. Ana II que trouxe a percepção de intervir em situações de desqualificação entre os/as educandos/as ao dizer que faz parte da educação antirracista o/a docente não se omitir e adotar uma postura não permissiva a "[...] apelidos e situações de constrangimento" (Profa. Ana II).

A educação antirracista, assim como compreende as professoras neste estudo e em acordo com Cavalleiro (2001; 2005), Gomes (2012) e Almeida (2018), exige um posicionamento político que confronta a naturalização destes episódios na sociedade e na escola, pois se dizer não racista, não irá superar o racismo e muito menos diminuir ou interromper o ciclo de violências sofridas por quem é oprimido pelo racismo na escola.

Tais compreensões acerca da educação antirracista na escola apresentados pelas docentes nos possibilitam vislumbrar o seu enfrentamento, discutidas a seguir.

\section{B) PráXis PedagógiCa antirRaCista na EduCaÇão Física Escolar}

Nessa categoria colocamos em cena as ações pedagógicas na perspectiva antirracista que as professoras empreendem no dia a dia de suas aulas, buscando compreender como as realizam e desvelar como significam essas experiências. 
Os conteúdos curriculares da Educação Física, dentre os quais, jogos, brincadeiras e danças, apareceram frequentemente nas respostas das participantes, destacadamente as culturas africanas, e indígenas, pois como ressalta a Profa. Andreia "[...] todos temos uma herança cultural advinda da cultura africana e indígena", as quais não podem permanecer invisibilizadas.

Tal compreensão é compartilhada pela Profa. Flavia que utiliza-se de jogos e brincadeiras para gerar um momento de reflexão entre os/as educandos/as: "[...] essas discussões são ressaltadas valorizando nossa cultura".

Chama a atenção a diversidade étnico-racial identificada pelas professoras em suas turmas, pois todas mencionaram a presença de educandos/as negros/as e três delas (Ana I, Ana III e Andreia) destacaram também a presença de educandos/as indígenas, conferindo ainda mais relevância aos conteúdos destacados por elas de modo a contemplar a diversidade racial observada pelas professoras em suas turmas.

Nesse sentido, a preocupação em contemplar essa diversidade para que as crianças reconheçam a sua ancestralidade, se revela na fala da Profa. Ana I, quando menciona que é preciso promover nas aulas de educação física "[...] situações e atividades que os alunos se reconheçam".

Convém situar a luta e a resistência dos descendentes de africanos e indígenas escravizados em meio ao processo de apagamento que foi instaurado pelo colonialismo como vimos no diálogo com Grosfoguel (2020) e Santos e Nunes (2003). Processo esse que desencadeou gerações de descendentes de africanos no Brasil que não conhecem sobre sua ancestralidade ou não de forma valorizada, como ressalta Profa. Ana I "[...] não ter tido isso durante meu crescimento. Acredito que faça toda diferença na vida da criança".

Essa problemática também é pontuada pela Profa. Andreia: “[...] muitos alunos/as participantes não conheciam suas origens [...]" como também observamos no trabalho realizado por Maranhão (2009).

Esse dado se torna alarmante uma vez que a escola pode contribuir através de uma educação antirracista, que potencialize o sentimento de pertencimento e orgulho de estudantes negros, assim como destacou Profa. Rebeca após a realização de um projeto em sua escola: "[...] pude ver a cultura africana e afro-brasileira valorizada e os alunos negros também sentiram-se pertencentes", resultado também observado por Profa. Fernanda: "Essas práticas sempre trazem uma valorização e um pertencimento aos alunos".

A este respeito é imprescindível uma reflexão mediante a responsabilidade da atuação docente e de toda comunidade escolar frente à realidade de nossos/as estudantes negro/as, visto que "O olhar lançado sobre o negro e sua cultura, na escola, tanto pode valorizar identidades e diferenças quanto pode estigmatizá-las, discriminá-las, segregá-las e até mesmo negá-las" (GOMES, 2003, p. 171-172).

Interessante observar que o enaltecimento das manifestações de matrizes africanas, afro-brasileiras e indígenas destacadas nos trabalhos de Maranhão (2009) e Silva (2019) atravessam todos os relatos dando destaque para tais conteúdos na escola, como revela a Profa. Juliana ao ressaltar que "[...] despertar em toda a comunidade escolar (educandos/as, familiares, gestão escolar, professoras) a valorização dessas culturas" enquanto que no caso da Profa. Fernanda, uma de suas iniciativas foi "[...] proporcionamos um sábado com várias atividades confecção da boneca abayomi, jogos e brincadeiras africanas na quadra, rodas cantadas".

As professoras relataram sua preocupação em propor as temáticas étnico-raciais de maneira consistente e valorizada, ao planejar diferentes estratégias didáticas, inclusive com utilização de recursos audiovisuais, como podemos analisar com Profa. Ana III: "Acredito que o audiovisual (assistir vídeos sobre o tema) tem um impacto maior, atinge com mais eficiência as pessoas, marcando-as mais com a emoção". 
Tais recursos também são destacados pela Profa. Fernanda, a qual ressalta ser importante aprofundar no conteúdo "[...] contextualizando sobre o continente africano, histórias, artigos, vídeos, desenhos".

A Profa. Ana III reconhece que o uso do audiovisual é uma possibilidade interessante, uma vez que, contribuem para despertar a empatia ao "[...] te colocar na situação da pessoa, de sentir emoções ao passar por uma determinada situação [...] essa foi uma das formas encontradas para despertar sensibilidade dos/as educandos/as para o assunto, aproximando-os da realidade de pessoas negras".

Ao tecer nossa análise sobre a práxis aqui narrada pelas professoras, fomos conduzidas às reflexões de Silva (2007):

Como se vê, é complexa, mas não impossível, a tarefa de tratar de processos de ensinar e de aprender em sociedades multiétnicas e pluriculturais, como a brasileira. Abordá-los pedagogicamente ou como objeto de estudos, com competência e sensatez, requer de nós, professores (as) e pesquisadores (as): não fazer vista grossa para as tensas relações étnico-raciais que "naturalmente" integram o dia-a-dia de homens e mulheres brasileiros; admitir, tomar conhecimento de que a sociedade brasileira projeta-se como branca; ficar atento(a) para não reduzir a diversidade étnico-racial da população a questões de ordem econômico-social e cultural; desconstruir a equivocada crença de que vivemos numa democracia racial. E, para ter sucesso em tal empreendimento, há que ter presente as tramas tecidas na história do ocidente que constituíram a sociedade excludente, racista, discriminatória em que vivemos e que muitos insistem em conservar (p. 492-493).

A realização dos projetos potencializando o envolvimento para além dos/as educandos/as, também suas famílias, se mostrou relevante na práxis pedagógica das professoras, em particular da Profa. Juliana, cujo projeto priorizou "[...] metodologias ativas para que os/as educandos/as estivessem no centro do processo educativo [...] tornando a aprendizagem marcante para os/as educandos, como também para suas famílias".

Projetos estes que oportunizam aos educandos/as o protagonismo, estímulo à autonomia, possibilitando a construção de conhecimentos também entre seus pares, como destaca a Profa. Rebeca: "Um projeto que realizamos "Ubuntu", onde trabalhamos com os quintos anos e finalizamos com um dia onde estes alunos ensinaram os alunos das demais salas da escola".

A realização de projetos integrando diferentes componentes curriculares foi outro aspecto reconhecido como valorativo pelas professoras, dentre elas, Profa. Flavia que mencionou: "[...] Participei de um projeto com várias disciplinas sobre os indígenas e foi bem marcante" e Profa. Juliana, cuja realização do projeto em sua escola, entrelaçou os conhecimentos da educação física com: “[...] História, Geografia, Língua Portuguesa e Arte [...] integrando outras áreas do conhecimento".

Em consonância com os achados na pesquisa de Silva (2005) os relatos denotam que o trabalho coletivo, que envolva toda a comunidade escolar, proporciona aos professores/as apoio, troca de experiências e aprendizados que geram consistência à educação antirracista e, aos educandos/as construção de conhecimento de forma contextualizada e valorizada, de cujo processo se percebem parte e corresponsáveis.

Outro aspecto que emergiu dos relatos mostrou possibilidades de buscar conhecimentos, junto a coletivos, como possibilitado pela Profa. Ana II: "No ano passado convidamos o 'Rpretas', movimento negro feminino, para um bate papo com os alunos de Fundamental II" e a comunidades indígenas com destacou a Profa. Flavia: "[...] conseguimos fazer uma visita na aldeia de Avaí e os alunos amaram, desmistificaram muitos preconceitos". 
Ao lançarmos luzes sobre a práxis pedagógica antirracista nas aulas de educação física a partir destas narrativas, notamos como as professoras percebem seu fazer pedagógico imbuído do potencial de transformação, no interior de um trabalho comprometido e engajado em promover a democratização dos conhecimentos e enfrentar a desigualdade racial na escola.

\section{CONSIDERAÇÕES}

As narrativas docentes acerca da educação antirracista na educação física escolar permitiu situá-la ancorada na "práxis" concebida por Paulo Freire (2005), como a busca incessante pela transformação das condições de opressão.

$\mathrm{O}$ envolvimento e engajamento das professoras, buscando o protagonismo dos/a educandos/as na apropriação crítica dos conhecimentos, bem como, envolvimento de toda comunidade escolar, expressa o posicionamento político de enfrentamento e não de acomodação ao racismo estrutural, assumindo esse envolvimento como primordial em seu fazer pedagógico na escola.

Acreditamos que, sendo o racismo estrutural, a educação antirracista como processo revolucionário de transformação das estruturas de poder prescinde da "práxis", pois como alerta Freire (2005) não há revolução com verbalismo "[...] mas com práxis, portanto, com reflexão e ação incidindo sobre as estruturas a serem transformadas" (p. 70).

A centralidade do diálogo e da reflexão na práxis das professoras foi um aspecto marcante que nos possibilita compreender a preocupação em democratizar os conhecimentos da Educação Física, com a fruição de manifestações culturais de matrizes africanas e indígenas, a partir de suas histórias e origens, contribuindo para desconstruir estereótipos e preconceitos, rompendo com os estigmas que inferiorizam e invisibilizam estes povos e suas culturas.

Vislumbramos um cenário em que essa rede de docentes comprometidos com a educação antirracista, seja ampliada e contemple todos os componentes curriculares e em muito mais escolas. Para tanto, sinalizamos o imprescindível fomento para a formação continuada de docentes com investimentos na capacitação e cursos de atualização profissional em serviço, como previsto nas Diretrizes Curriculares para a Educação das Relações ÉtnicoRaciais, propiciando conhecimento, segurança e apoio aos docentes para realizar o trabalho pedagógico com alicerce e que envolva a comunidade escolar como um todo.

Busquemos resgatar o direito de ser de todos e todas na escola em um esforço conjunto de toda sociedade e do poder público para oportunizar uma educação equânime que enfrente o racismo e as desigualdades, fazendo da Escola uma instituição que se oriente pelo respeito às diferenças e o sentimento de comunidade, pilares para uma educação para a paz.

\section{REFERÊNCIAS}

ALMEIDA, S. L. O que é racismo estrutural? Belo Horizonte: Letramento, 2018.

BRASIL. Ministério da Educação/Secad. Diretrizes curriculares nacionais para a educação das relações étnico-raciais e para o ensino de história e cultura afro-brasileira e africana na educação básica. Brasília: MEC, 2004.

BRASIL. Lei 11.645 de 10 de março de 2008. Altera a Lei no 10.639, de 3 de janeiro de 2003. Disponível em: http://www.planalto.gov.br/ccivil_03/_ato2007-2010/2008/lei/111645.htm. Acesso em: 30 nov. 2021. 
Denise Aparecida Corrêa; Paloma de Campos Rodrigues

BRASIL. Secretaria de Educação Fundamental. Parâmetros curriculares nacionais: educação física. Brasília: MEC/SEF, 1997.

CAVALLEIRO, E. Discriminação racial e pluralismo nas escolas públicas da cidade de São Paulo. In: BRASIL. Ministério da Educação/SECADI. Educação e anti-racismo: caminhos abertos pela Lei Federal 10.639/03. Brasília: SECAD/MEC, 2005. p. 65-104.

CAVALLEIRO, E. Educação antirracista: compromisso indispensável para um mundo melhor. In: CAVAllEIRO, E (org.). Racismo e anti-racismo na educação: repensando nossa escola. São Paulo: Selo Negro, 2001. p. 141-160.

CORRÊA, D. A; SILVA, M. G. A; CARVALHO, F. B. Jogos de tabuleiro africanos: tradição e diversão no ensino médio. Revista Brasileira de Estudos do Lazer, v. 7, n. 2, p. 64-83, 2020.

COSTA, B. R. L. Bola de neve virtual: o uso das redes sociais virtuais no processo de coleta de dados de uma pesquisa científica. Revista Interdisciplinar de Gestão Social, v. 7, n. 1, p. 15-37, 2018.

FREIRE, P. Pedagogia do oprimido. 43. ed. Rio de Janeiro: Paz e Terra, 2005.

GOMES, N. L. Relações étnico-raciais, educação e descolonização dos currículos. Currículo sem fronteiras, v. 12, n. 1, p. 98-109, 2012.

GOMES, N. L. Diversidade étnico-racial, inclusão e equidade na educação brasileira: desafios, políticas e práticas. Revista Brasileira de Política e Administração da Educação, v. 27, n. 1, p. 109-121, 2011.

GOMES, N. L. Educação, identidade negra e formação de professores/as: um olhar sobre o corpo negro e o cabelo crespo. Educação e pesquisa, v. 29, n. 1, p. 167-182, 2003.

GOMES, R. A análise de dados em pesquisa qualitativa. In: MINAYO, M. C. S. (org.). Pesquisa Social: teoria, método e criatividade. Petrópolis: Vozes, 2004. p. 67-80.

GROSFOGUEL, R. Para uma visão decolonial da crise civilizatória e dos paradigmas da esquerda ocidentalizada. In: BERNARDINI-COSTA, J; MALDONADO-TORRES, N; GROSFOGUEL, R. (org.). Decolonialidade e pensamento afrodiaspórico. 2. ed. Belo Horizonte: Autêntica, 2020. p. 55-77.

MARANHÃO, F. Jogos africanos e afro-brasileiros nas aulas de educação física: processos educativos das relações étnico-raciais. 2009. 173 f. Dissertação (Mestrado em Educação) - Centro de Educação e Ciências Humanas, Universidade Federal de São Carlos, São Carlos, 2009.

MARANHÃO, F; GONÇALVES JUNIOR, L. Jogos africanos e afro-brasileiros na educação física escolar: processos educativos inter-étnicos. In: COLÓQUIO DE PESQUISA QUALITATIVA EM MOTRICIDADE HUMANA, 4., 2009, São Carlos. Anais [...]. São Carlos, 2009. p. 252-265. Disponível em: http://motricidades.org/conference/index.php/cpqmh/issue/view/4cpqmh/4. Acesso em: 29 nov. 2021.

MARANHÃO, F; GONÇALVES JUNIOR, L; CORRÊA, D. A. Jogos e brincadeiras africanos nas aulas de educação física: construindo uma identidade cultural negra positiva em crianças negras e não negras. In: JORNADAS DE JÓVENES INVESTIGADORES DE LA AUGM, 15., 2007, Asunción. Actas [...]. Asunción, 2007. (CDROM).

MARCONI, M. A.; LAKATOS, E. M. Fundamentos de metodologia científica. São Paulo: Editora Atlas, 2003.

MIRANDA, L. L. R. N. Atuação docente antirracista nas aulas de educação física. 2017. 93 f. Trabalho de Conclusão de Curso (Licenciatura em Educação Física) - Faculdade de Educação Física, Universidade Estadual Paulista Júlio de Mesquita Filho, Bauru, 2017.

MOTA, J. S. Utilização do Google Forms na pesquisa acadêmica. Revista Humanidades e Inovação, v. 6, n. 12, p. 371-380, 2019. 
NEGRINE, A. Instrumentos de coleta de informações na pesquisa qualitativa. In: MOLINA NETO, V; TRIVIÑOS, A. N. S. (org.). A Pesquisa qualitativa na educação física: alternativas metodológicas. Porto Alegre: Editora Universidade/ UFRGS/ Sulina, 1999. p. 61-93.

OliveirA, A. G. S; SOAREZ, A. C. A. M; OliveirA, G. A; SANTOS, N. L; SilVA, L. A. Processos educativos desvelados no conviver: curso equidade. Motricidades: Revista da Sociedade de Pesquisa Qualitativa em Motricidade Humana, v. 4, n. 2, p. 167-179, 2020. Disponível em: https://motricidades.org/journal/index.php/journal/article/view/2594-6463.2020.v4.n2.p167-179. Acesso em: 29 nov. 2021.

RANGEL, I. C. A. Racismo, preconceito e exclusão: um olhar a partir da Educação Física escolar. Motriz, v. 12, n. 1, p. 73-76, 2006.

RIBEIRO, D. Pequeno manual antirracista. São Paulo. Companhia das Letras, 2019.

RODRIGUES, P. C.; CORRÊA, D. A. Representatividade negra nas histórias de princesas. Revista África e Africanidades, v. 14, n. 39, p. 93-108, 2021. Disponível em: https://africaeafricanidades.online/documentos/dossiearteeliteratura2021.pdf\#page=94. Acesso em: 30 nov. 2021.

SANTOS, B. S. Reconhecer para libertar: os caminhos do cosmopolitismo multicultural. Rio de Janeiro: Civilização Brasileira, 2003.

SANTOS, B. S; NUNES, J. A. Introdução: para ampliar o cânone do reconhecimento, da diferença e da igualdade. In: SANTOS, B. S. (org.). Reconhecer para libertar: os caminhos do cosmopolitismo multicultural. Rio de Janeiro: Civilização Brasileira, 2003. p. 25-68.

SANTOS, M. V. O estudante negro na cultura estudantil e na educação física escolar. 2007. 240 f. Dissertação (Mestrado em Ciências do Movimento Humano) - Escola de Educação Física, Universidade Federal do Rio Grande do Sul, Porto Alegre, 2007.

SILVA, N. F. I. Africanidade e religiosidade: uma possibilidade de abordagem sobre as sagradas matrizes africanas na escola. In: BRASIL. Ministério da Educação/SECADI. Educação anti-racista: caminhos abertos pela Lei Federal no 10.639/03. Brasília: MEC, 2005. p. 121-130.

SILVA, P. B. G. Aprender, ensinar e relações étnico-raciais no Brasil. Educação, Porto Alegre, v. 30, n. 3, p. 489-506, 2007. Disponível em: https://revistaseletronicas.pucrs.br/ojs/index.php/faced/article/view/2745/2092. Acesso em: 01 dez. 2021.

SILVA, R. B. S. Jogos de tabuleiro africanos na educação física escolar: possibilidades pedagógicas. 2019. 43 f. Trabalho de Conclusão de Curso (Licenciatura em Educação Física) - Faculdade de Educação Física, Universidade Estadual Paulista Júlio de Mesquita Filho, Bauru, 2019.

SILVA, S. M. Imagens de africanidade: uma leitura de mundo anti-racista. Rio de Janeiro, 2003. Dissertação (Mestrado em Educação) - Faculdade de Educação, Universidade do Estado do Rio de Janeiro, 2003.

Recebido em: 01 dez. 2021.

Aprovado em: 21 jan. 2022. 